\title{
Foreword
}

\section{Where do we find ourselves?}

My title is drawn from the first line of Ralph Waldo Emerson's great essay "Experience." It is a question perhaps even more salient in our times than it was in his. It is in the context of that question that Ilan Zvi Baron has written a book that confronts this question directly, both as diagnosis and as prescription. This is a book, I may say, that we have been, or should have been, waiting for. It is written not only for those who are distressed with the election of Donald Trump and the Brexit decision in the United Kingdom, but even more importantly, for those who are not distressed by the two events. Drawing upon a very wide range of material - from philosophy, from political science, from economics, from literature, from international relations - he faces head on the problem of our relation to politics in a "post-truth" age. For ours is an age in which it appears, as a Trump spokesperson once said, that "anything is true if enough people believe it."

The novel move in Baron's book is not to discount such claims as "scientifically" silly, but to accept the reality that any claim of fact is potentially defeasible. Hannah Arendt - one of the major voices here - had said as much. Hence our world is increasingly characterized as "post-truth." The consequence of this - and this is Baron's starting point - is that many of us increasingly have the sense that the world is falling apart and that all responses to that experience seem pointless. This is not just an issue for "left-leaning" folk: neither we nor those who voted for Trump or Brexit have much faith in the state any more. As I write, positive support for the US Congress is at $11 \%$. 
Baron identifies several failures consequent to this situation. The legitimacy of "normal" modern politics seems at best tenuous; our politics is manifestly unable to address seriously and democratically the world of global capitalism; the dominant economic and neoliberal powers seem to be beyond control. An important contribution of this book is also to show that much contemporary political theory, especially liberal political theory, does not and cannot deal with these failures convincingly.

Baron's formation places him well to address the complexity of these issues. He is not only well versed in political theory, both the canon and contemporary material, but also in a wide range of philosophical thought, particularly phenomenology, as well as in Jewish thought and experience ("saving politics" is not irrelevant to contemporary Israeli experience). He has worked with several NGOs in Geneva and Zurich. A central theme throughout his work in these areas has been the question of responsibility, not only in terms of who is responsible, but, more importantly, of how ones assumes responsibility for oneself.

How does his formation shape the claims of this book? The problems we face, he writes, are not primarily economic (though they are not not economic), but they are political and social-cultural. Let us look at his argument about "post-truth."

Whether or not there is "the" truth, knowing the truth is in any case not the primary problem. It is rather "acknowledging it" - I borrow the term from Stanley Cavell, one of the thinkers who appear in Baron's book. What does this mean? Picture: you are late. You know you are late. I know you are late. I know you know you are late. You know I know you know you are late - an ethical version, perhaps, of the third man problem in philosophy. Such knowledge is not enough. You have to do something appropriate to the particular situation - in this case likely say something like: "I am sorry I was late, I ..." and file an appropriate excuse ("my child was sick"; "the car broke down"; "there was an accident on the highway"; but probably not "I was having too much fun in bed" or "I was abducted by aliens"). "Appropriate" means that you recognize the situation as another would. When Trump says something false, it is not that he does not know that it is false that matters, 
but that he does not, perhaps cannot, acknowledge it - that is, actually mean what he says. One cannot successfully call him on the "facts of the matter," that is, on it being "false." To mean actually what one says is the ground of responsibility. And to not mean what one says is to be missing something about oneself much more than it is an attempt to deceive.

Thus, what do those in power increasingly miss? This understanding has, for me and Baron, the consequence of making our political situation even more perilous than one might have thought. The problem is not that the administration lies; the problem is not that people do not or cannot deliberate. The problem is rather that the administration lacks any sense of responsibility to that human capacity that makes discourse public. Here "public" does not at first mean "true," but rather more something like what Kant meant: to speak as a human being and not as a socially defined role. To lack that responsibility is to be a tyrant.

Baron does not use the word "tyrant," but he might have. In what does our present tyranny consist? In the Persian Letters, Montesquieu argued that it consists in requiring that others have no existence for oneself except that which one allows them. This seems to me exactly right. What is missing in Trump et al. is an acknowledgement that there are those who, still to some shrinking degree, think that he (and much of the administration) is of the same community as others.

The emphasis on responsibility in Baron's book has a radical consequence. It means that, contrary to our still standard way of appraising judgments, the validity of a judgment or claim depends on the particular character of the person making that claim. In our age, we are required first to judge not the judgement but the judger. Baron unpacks this in a clear-headed way. Our life, he writes, may be said to be in some sense coordinated with the narrative of who we are and the positions we hold. Should we at some point not behave in a manner compatible with that narrative - say that out of deference to power we overlook an incidence of misogyny (one of Baron's examples) - we will to that degree be acting non-responsibly. This in turn leads Baron to develop a very interesting twist 
on the general question of identity as it relates to politics. Identity is important not so much as a fallback ground but in that what we know depends on who we are - and given the encomium about responsibility, there may be times that we do not act as who we are - and what we claim then to know cannot be authentically our own. Finally, there are, Baron argues, different facets of responsibility in relation to the question of identity: we can be liable for a choice; we can be complicit in going along with a choice that should not be ours, and we can be ontologically irresponsible, in that we have simple forgone being what or who we are.

Note that his argument is not a judgment about what policies might be preferable to follow. Baron is less concerned with that than he is concerned with the relation of human beings to the policies that they pursue and endure. His intention is to save politics, not to push for a particular policy. And the case he makes is convincing: without a redemption of politics, it will not matter what policy is pursued.

\section{Tracy B. Strong}

Professor of Political Thought and Philosophy, University of Southampton

Distinguished Professor Emeritus of Political Science, University of California, San Diego 